\title{
PEMANFAATAN PEKARANGAN RUMAH WARGA DENGAN TEKNIK BUDIDAYA TANAMAN KAKTUS HIAS
}

\author{
Dyah Pikanthi Diwanti
}

\author{
Dosen Universitas Muhammadiyah Yogyakarta \\ dyahpikanthidiwanti@gmail.com
}

\begin{abstract}
Turus Hamlet is one of the hamlets in Tanjungharjo Village, Nanggulan District, Kulonprogo Regency, which has potential in agriculture and crafts. This community empowerment program utilizes residents' yards to optimize land functions by cultivating ornamental cacti. This program is reasoned because there is an agricultural irrigation problem in Turus Hamlet, which is currently still under repair and has resulted in drought on the residents' agricultural lands. The purpose of holding this program is to empower the people of Turus Hamlet to gain insight/knowledge and independence by empowering the planting of ornamental cactus plants that have selling power. This activity's method is carried out with counseling, training, and mentoring to residents and farmer groups the results of empowerment; besides that, leaflets as educational tools are provided as a guide. The steps are: first, by first socializing about cactus plants to residents and farmer groups, secondly training on planting cacti strung on pots and growing media, which are the handicrafts of the residents. This program was continued with mentoring, namely monitoring the cactus results produced until the plants were ready to be sold. From the series of implementation of this activity, there are several indications of success, including the attitude of the residents who show a positive response to the importance of using the house yard, the enthusiasm of the residents/farmers, and the awareness of using the yard towards economic independence with the potential for selling ornamental cactus
\end{abstract}

Keywords: Yard, Ornamental Cactus Cultivation

\begin{abstract}
Abstrak
Dusun Turus merupakan salah satu dusun di Desa Tanjungharjo, Kecamatan Nanggulan, Kabupaten Kulonprogo yang memiliki potensi di bidang pertanian dan kerajinan. Program pemberdayaan masyarakat ini untuk memanfaatkan pekarangan rumah milik warga dalam rangka pengoptimalan fungsi lahan dengan budidaya kaktus hias . Program ini beralasan karena adanya permasalahan irigasi pertanian di Dusun Turus yang saat ini masih dalam perbaikan dan mengakibatkan kekeringan di lahan pertanian warga. Tujuan diadakannya program ini agar warga masyarakat Dusun Turus menambah wawasan / pengetahuan serta kemandirian dengan memberdayakan penanaman tanaman kaktus hias yang memiliki daya jual. Metode kegiatan ini dilaksanakan dengan penyuluhan, pelatihan dan pendampingan kepada warga dan kelompok tani dan untuk memaksimalkan hasil pemberdayaan selain itu leaflet sebagai sarana edukasi diberikan sebagai panduan. Adapun langkah-langkahnya: pertama dengan cara sosialisasi terlebih dahulu tentang tanaman kaktus kepada warga dan kelompok tani, kedua pelatihan penanaman Kaktus dirangkai pada pot dan media tanam yang merupakan hasil kerajinan warga. Program ini dilanjutkan dengan pendampingan yakni pemantauan hasil kaktus yang telah ditanam sampai pada kesiyapan tanaman untuk siyap dijual. Dari rangkaian pelaksanaan kegiatan ini ada beberapa indikasi keberhasilan yakni diantaranya sikap warga yang menunjukan respon positif akan pentingnya pemanfaatan pekarangan rumah , antusiasme warga / petani dan kesadaran untuk pemanfaatan pekarangan menuju kemandirian ekonomi dengan potensi penjualan kaktus hias.
\end{abstract}

Kata kunci: Pekarangan Rumah, Budidaya Kaktus Hias

MARTABE : Jurnal Pengabdian Masyarakat| 351 


\section{PENDAHULUAN}

Pemberdayaan masyarakat
merupakan program nyata yang dilakukan dalam bentuk KKN (Kuliah Kerja Nyata) sebagai perwujudan Tri Dharma dan Catur Dharma Perguruan Tinggi. Sebagai wujud penerapan pengetahuan yang telah dipelajari untuk kemajuan masyarakat, Perguruan tinggi memberikan fasilitas kepada masyarakat melalui program KKN untuk melakukan pengabdian kepada masyarakat. Pembangunan masyarakat semakin kuat dengan adanya agen perubahan yang melakukan perubahan inovasi yang terencana dengan program pemberdayaan.Pemberdayaan

masyarakai ini sangatlah sesuai dengan suasana atau kondisi masyarakat di Dusun Turus. Dusun Turus merupakan salah satu dusun yang termasuk dalam kecamatan Nanggulan kabupaten Kulonprogo Daerah Istimewa Yogyakarta. Dusun Turus memilik luas sekitar $5 \mathrm{~km} 2$ dengan jarak ke kabupaten Kulonprogo sekitar $8 \mathrm{~km}$. Dusun Turus memiliki 1 kepala Dukuh yang membawahi 6 Kepala RT dan 3 Kepala RW. Dusun Turus memiliki 2 kelompok Tani yakni kelompok tani Lestari dan kelompok Wanita tani Lestari dimana keduanya merupakan mitra dalam pelaksanaan budidaya Kaktus hias selain melibatkan organisasi kepemudaannya. Dusun Turus memiliki $118 \mathrm{Kk}$ dimana jumlah total warganya 438 jiwa dengan komposisi laki-laki 204 jiwa dan perempuan 224 jiwa. Program pemberdayaan masyarakat ini untuk memanfaatkan pekarangan rumah milik warga dalam rangka pengoptimalan fungsi lahan dengan budidaya kaktus hias . Program ini beralasan karena adanya permasalahan irigasi pertanian di Dusun Turus yang saat ini masih dalam perbaikan dan mengakibatkan kekeringan di lahan pertanian warga. Solusi dari permasalahan yang ada di masyarakat Dusun Turus adalah dengan peningkatan kapasitas dan pendampingan dalam pemanfaatan lahan melalui budidaya tanaman kaktus.

Kaktus adalah tanaman hortikultura yang dapat tumbuh lama tanpa air dan berasal dari benua Amerika. Tanaman ini merupakan salah satu tanaman hias yang banyak digemari masyarakat karena unik dan khas (Djafarer, 1987). Biasanya banyak ditemukan di daerah gersang (gurun). Kaktus merupakan tanaman yang hidup di padang pasir yang tumbuh subur dalam kondisi kering dan panas, tetapi tanaman ini juga bisa dijadikan tanaman hias yang mempercantik ruangan. Tnaman kaktus masuk dalam tanaman sukulen,karena kaktus bisa menyimpan persediaan air di batangnya, bentuk batangnya yang bervariasi menjadikan kaktus dapat tumbuh lama tanpa air. Kaktus juga memiliki daun yang berubah bentuk menjadi duri sehingga penguapan air melalui daun dapat dikurangi. Pemeliharaan Kaktus memerlukan perhatian yang tidak rumit seperti bagaimana cara meletakkan tanaman meskipun kaktus mampu bertahan ditempat yang kering namun tempat meletakkan tidak bisa langsung dibawa terik matahari, memastikan sirkulasi udara berjalan lancar dan tidak lembap yakni bisa menambahkan pasir sebagai media tanamnya supaya kaktus bisa beradaptasi dengan baik. Selain itu, memberikan pupuk agar kaktus bisa tumbuh dengan sehat dan cantik tentunya dengan menggunakan pupuk organik. Hal lain yang bisa dimunculkan dari budidaya kaktus ini adalah kaktus dalam pot membutuhkan lebih banyak perawatan dalam penyiraman daripada di tanah. Ketika di rumah, penyiraman bisa dilakukan 
Dyah Pikanthi Diwanti. Pemanfaatan Pekarangan Rumah Warga Dengan Teknik...

sebulan sekali tergantung pada kelembapan ruangan. Tetapi jika tanaman ini diletakkan di luar rumah, siramlah setiap dua atau tiga hari. Pastikan tanah terlihat sedikit mengering saat disiram.

Banyak macam jenis kaktus hias seperti kaktus mini Ariocarpus. Kaktus ini berbeda dengan kaktus lainnya karena kebanyakan tanaman kaktus lain yang sangat identik dengan duri namun tanaman kaktus jenis ini justru tidak memiliki duri sama sekali. Malah kaktus ini dominan karena daunnya yang membentuk prisma dengan ukuran bunga besar dan mencolok. Masih banyak jenis kaktus hias lain seperti Astrophytum, Cephalocereus senilis, dan Gymnocalycium yang cocok sebagai tanaman hias untuk di budidayakan. Dan inilah upaya yang dilakukan dalam pemanfaatan lahan pekarangan warga dusun Turus Kulonprogo dengan budidaya tanaman kaktus.

\section{METODE PELAKSANAAN}

Metode pelaksanaan dilakukan dengan penyuluhan, pelatihan dan pendampingan kepada Warga dan kelompok tani Lestari untuk memaksimalkan hasil pemberdayaan. Adapun langkah pertama, Jasa penyuluhan tanaman rumah tangga dengan budidaya kaktus bagi warga petani/ kelompok tani diikuti oleh 75\% anggota. Kegiatan ini dilakukan dengan mengumpulkan warga bersama anggota Kelompok Tani. Kedua , Jasa pelatihan tanaman rumah tangga diikuti oleh 75\% anggota. Pelatihan dengan langsung praktek cara penanaman dan perawatan tanaman melalui pot/ tanah sebagai media. Ketiga, Jasa pendampingan pengelolaan tanaman rumah tangga dimana terdapat warga petani diikuti oleh warga dan kelompok tani.
Dilakukan pendampingan dalam pengelolaan dengan budidaya kaktus Pendampingan dan monev Kegiatan ini dilakukan secara periodik untuk membina dan mendampingi mitra. Leaflet pemanfaatan pekarangan Rumah warga Dengan Teknik Budidaya Tanaman Kaktus hias..

Adapun langkah-langkah yang dilakukan:

1) Sosialisasi, Sosialisasi dilaksanakan untuk menambah wawasan dan ilmu masyarakat setempat bahwa terdapat potensi yang dapat dikembangkan, baik dari segi SDA maupun SDMnya. Sosialisasi juga dilaksanakan untuk mengatasi permasalahan yang ada di Dusun Turus diantaranya kurangnya minat masyarakat memanfaatkan pekarangan rumah serta pemanfaatan tanaman yang mampu bertahan dilokasi kering. Sosialisasi berupa sosialisasi untuk budidaya tanaman kaktus target sasaran warga dan kelompok tani Dusun Turus.

2) Pelatihan. Pelatihan dilaksanakan untuk program pokok (Pemberdayaan masyarakat) dimana dengan praktik langsung untuk mencapai tujuan yang bersifat psikomotorik. Pelatihan mendatangkan narasumber dari pihak luar (pemateri) dan dari mahasiswa pelaksana KKN dari fakultas pertanian dan pemuda setempat yang sudah memiliki usaha dibidang usaha kaktus. Pelatihan yang akan dilaksanakan yaitu, Pembuatan pot alami yang digunakan sebagai media untuk budidaya tanaman kaktus dengan target sasaran warga dan kelompok tani.

3) Pendampingan, dilakukan pendampingan dalam pengelolaan budidaya kaktus yang ada dipolibag untuk selanjutnya bisa dilakukan 
secara mandiri. (Gambar 3 Pendampingan Budidaya Kaktus)

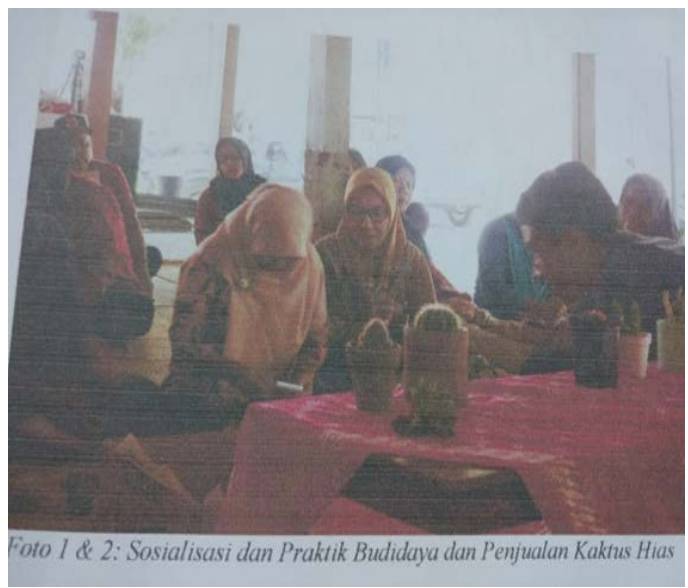

Gambar 1. Pelatihan Budidaya Kaktus

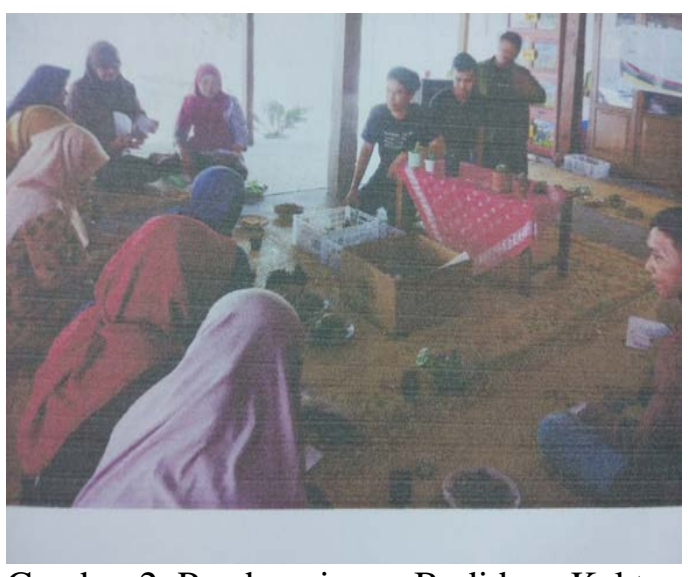

Gambar 2. Pendampingan Budidaya Kaktus

\section{Pembuatan Leaflet Cara} Pemanfaatan Pekarangan Rumah Warga Dengan Teknik Budidaya Tanaman Kaktus Hias

Untuk

mempermudah pemanfaatan pekarangan rumah warga maka diperlukan panduan. Panduan berupa leaflet dibagikan kepada warga khususnya kelompok tani yang senantiasa belajar.

Adapun hasil pelaksanaan:

1) Penanaman, dilakukan dengan menyediakan media tanam yakni pot dan tanaman kaktus, mengisi 1/3-1/2 pot dengan media tanam, meletakkan tanaman kaktus pada pot yang sudah diisi media tanam, tidak memberinya air selam 24 jam selesai penanaman, setelah 24 jam disiram dengan ukuran yang tidak berlebih.

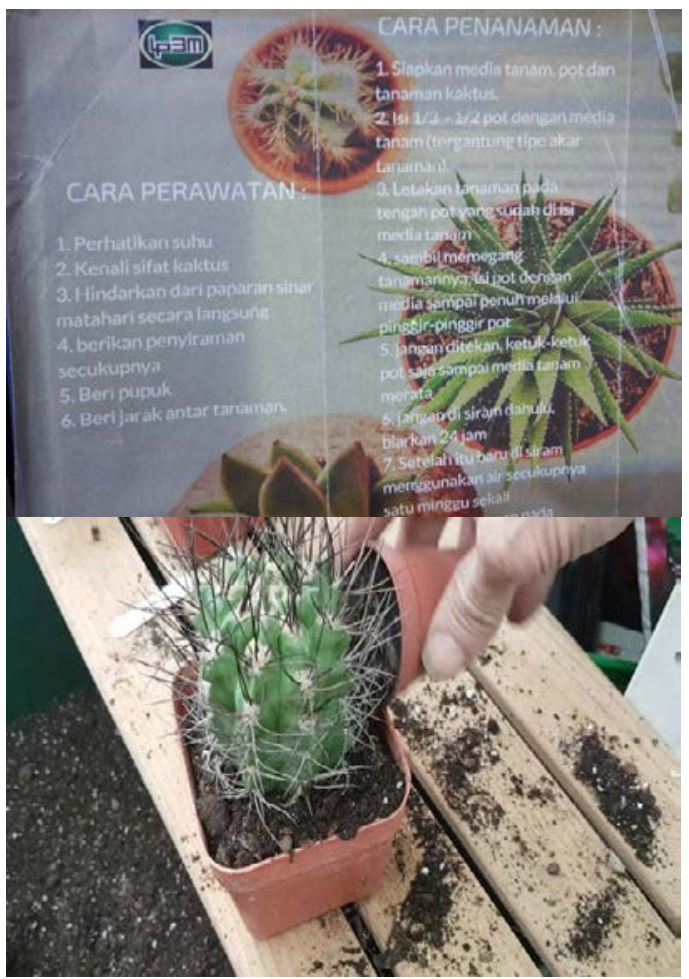

Gambar 3. Leaflet Budidaya Kaktus

2) Pemeliharaan, dilakukan dengan memperhatikan suhu/ kondisi cuaca, mengenai sifat kaktus dengan ragam jenisnya, menghindari secara langsung dari terik matahari, memberikan penyiran air secukupnya, memberikan jarak antar tanaman.

\section{Capaian Pelaksanaan Program Pemanfaatan Pekarangan Rumah Warga Dengan Teknik Budidaya Tanaman Kaktus Hias}

Capaian kegiatan ini terindikasi dari pertama perubahan mindset warga akan pemanfaatan pekarangan rumah dengan teknik budidaya tanaman kaktus dan ini dapat dilihat dari antusias warga dalam mengikuti kegiatan pelatihan dan pendampingan kegiatan.

Kedua.Pemanfaatan lahan yang tidak produktif menjadi lahan produktif dimana terlihat dari keterlibatan $23 \mathrm{kk}$ 
Dyah Pikanthi Diwanti. Pemanfaatan Pekarangan Rumah Warga Dengan Teknik...

warga dusun Turus yang mampu melakukan kegiatan di pekarangan rumah mereka dan memanfaatkan lahan kosong untuk budidaya tanaman yang mampu bertahan ditempat kering.

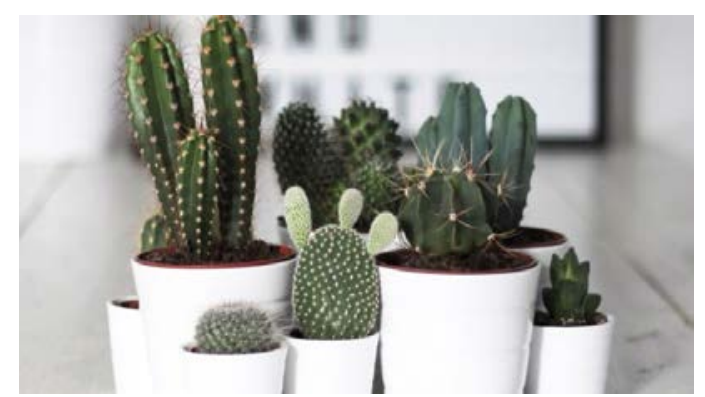

Gambar 4. Budidaya Kaktus di Rumah

\section{SIMPULAN}

Dari rangkaian pelaksanaan kegiatan pemanfaatan pekarangan rumah , ada beberapa indikasi keberhasilan dari program tersebut. Di antaranya sikap warga yang menunjukan perubahan positif yaitu adanya peningkatan kesadaran warga yang mayoritas petani akan pentingnya pemanfaatan pekarangan untuk penanaman tanaman kaktus, antusiasme warga/ petani dan kesadaran untuk pemanfaatan lahan pekarangan. Selain itu menghasilkan suatu produk panen tanaman yang dilengkapi dengan leaflet sebagai sarana edukasi tentang bagaimana proses Budidaya Kaktus.

Berdasarkan program ini menunjukan bahwa pemanfaatan pekarangan rumah untuk peningkatan kesejahteraan masyarakat dapat dilakukan dalam kondisi apapun selama kreativitas dan inovasi menjadi poin penting.

\section{UCAPAN TERIMA KASIH}

Terima kasih kami ucapkan kepada Lembaga Pendidikan, Penelitian dan Pengabdian pada Masyarakat (LP3M) UMY atas penyelenggaraan KKN,
Pemerintah Kabupaten Kulonprogo beserta aparat dari Kelurahan sampai RT dan RW Dusun Turus, Mitra Kelompok Tani dan Masyarakat Dusun Turus

\section{DAFTAR PUSTAKA}

Djafarer,R,Kaktus-kaktus yang mempesona dalam Trubus, Jakarta,1987

Dyah Pikanthi Diwanti, Pengembangan Potensi Masyarakat melalui pemberdayaan pertanian organik. Jurnal Berdikari UMY vol.6 no.1 Feb 2018

Dyah Pikanthi Diwanti, Pemanfaatan Pertanian Rumah Tangga dengan Teknik Budidaya tanaman sayuran secar vertikultur. Jurnal Martabe vol.1 no.3 2018

Endah, J dan tim Lentera, Mempercantik Kaktus dan Meningkatkan Nilai jualnya, agromedia Pustka, Jakarta,2002

Gatot Supangkat dan Moch Nurcholis,2013.

Pengembangan Sistem Pertanian Terpadu berbasis Masyarakat di Kecamatan Kalibawang, Kabupaten Kulonprogo, Jurnal Berdikari, UMY

Joesi Endah\&Tim, Mempercantik Kaktus dan Meningkatkan Nilai Jualnya. 2005 Agromedia Pustaka .Jakarta

Lakitan , Hortikultura teori Budidaya dan Pasca Panen, Raja Grafindo Pustaka,1995

Maisarah, Panduan Budidaya Kaktus,2014,Penerbit Indoliterasi

Rahman Sutanto, 2002. Pertanian organik menuju pertanian 
MARTABE : Jurnal Pengabdian Masyarakat Vol 4 No 1 Tahun 2021 Hal 351-356

alternatif dan berkelanjutan.

Kanisius. Yogyakarta 218 hal

Yuliana, Kaktus cantik dan Unik, 2015, Penebar Swadaya

https://www.kampustani.com

Budidaya kaktus untuk pemula

https://www.tribunnews.com

Kiat www.agrowindo.com Peluang Usaha Budidaya Kaktus

https://peluangusaha.kontan.co.id

Kaktus Mini

memelihara tanaman kaktus 